\title{
The Role of Nitric Oxide in Development of Topographic Precision in the Retinotectal Projection of Chick
}

\author{
Hope H. Wu, ${ }^{1}$ Daniel J. Selski, ${ }^{1}$ Esam E. El-Fakahany, ${ }^{2}$ and Steven C. McLoon ${ }^{1}$ \\ ${ }^{1}$ Department of Neuroscience, and 2Department of Psychiatry, University of Minnesota, Minneapolis, Minnesota 55455
}

The axonal projection from the retina to the tectum exhibits a precise topographic order in the mature chick such that neighboring ganglion cells send axons to neighboring termination zones in the contralateral tectum. The initial pattern formed during development is much less organized and is refined to the adult pattern during a discrete period of development. Refinement includes elimination of radically aberrant projections, such as those from the temporal side of the retina to posterior regions of the tectum, as well as a more subtle improvement in the topographic precision of the projection. The enzyme that synthesizes nitric oxide is expressed at high levels in the tectum during the developmental period in which the topography im-

Axons of retinal ganglion cells project to the primary visual centers of the brain in a precise pattern in mature vertebrates. The two-dimensional distribution of the ganglion cells across the retina is approximately recreated in the pattern of their terminals in the brain. A considerable body of work has begun to reveal the mechanisms responsible for development of this topographic pattern of connections. The retinotectal projection has served as a model system for much of this work. Molecules distributed in gradients across the developing retina and the tectum serve as positional markers that specify the approximate position in which retinal axons stop growing and form initial connections in the brain (for review, see O'Leary and Wilkinson, 1999). Although positional labels are clearly important, other mechanisms are also required.

The early developmental pattern of the retinotectal projection in some species lacks the precision of the adult projection, and activity-dependent mechanisms appear to be involved in refinement of the early pattern. In early development of the chick for example, the adult pattern of the retinotectal projection can be discerned, but many retinal axons project to topographically inappropriate regions of the tectum (McLoon, 1982; Nakamura and O'Leary, 1989). The early retinotectal projection in rodent is even more disorganized (Simon and O'Leary, 1992). The embryonic projection pattern is refined after ganglion cells begin to fire action potentials. During the same developmental period in which the topographic precision of the retinotectal projection improves, the projections from the two eyes segregate into separate termination zones within the primary visual centers (Land and Lund, 1979; McLoon and Lund, 1982; O'Leary et al., 1983; Cowan et

Received Dec. 22, 2000; revised March 20, 2001; accepted March 29, 2001.

This work was supported by National Institutes of Health Grants EY06734 and EY11926.

Correspondence should be addressed to Steven C. McLoon, Department of Neuroscience, University of Minnesota, 6-145 Jackson Hall, 321 Church Street SE, Minneapolis, MN 55455. E-mail: mcloons@tc.umn.edu.

Copyright (c) 2001 Society for Neuroscience 0270-6474/01/214318-08\$15.00/0 proves. Pharmacological blockade of nitric oxide synthesis during this period prevented elimination of topographically inappropriate retinotectal projections in a dose-dependent manner. This effect could not be duplicated by treatment of embryos with a vasoconstrictor, indicating that vascular changes were not a factor. These results show that nitric oxide is involved in refinement of the topography of the retinotectal projection as well as in other aspects of refinement of this projection in developing chick.

Key words: nitric oxide synthase; retina; tectum; pattern formation; refinement of connections; neuronal development al., 1984; Williams and McLoon, 1991). The mechanisms involved in these two types of refinement are not completely understood. Because both types of refinement take place at the same time and are similar in nature, it is possible that they are controlled by the same mechanisms.

Nitric oxide (NO) is involved in segregation of the projections from the two eyes in some species. In developing chick, pharmacological blockade of NO synthesis prevented complete elimination of the transient ipsilateral retinotectal projection (Wu et al., 1994). Similar findings were obtained in rat with drug treatments like those used in the chick study (Campello-Costa et al., 2000; Vercelli et al., 2000) and in mouse with knock-outs of the genes responsible for synthesis of NO in the brain (Wu et al., 2000). In ferret, NO is essential for segregation of on/off pathways in the lateral geniculate nucleus; it does not appear, however, to be required for segregation of the projection from the two eyes in the retinogeniculate projection (Cramer et al., 1996; Cramer and Sur, 1999). The question remains as to whether NO is involved in refinement of the topography of the retinotectal projection. Given the dichotomy exhibited by these examples of refinement of retinofugal projections, it seems equally possible that NO is or is not involved in topographic refinement in the retinotectal system.

The aim of this study was to test whether NO is involved in refinement of the topography of the chick retinotectal projection during development. Synthesis of NO was inhibited pharmacologically during the period of development in which the topographic precision of the retinotectal projection normally improves. Unlike controls, the retinotectal projection of these embryos late in development retained topographic errors typical of early embryos.

\section{MATERIALS AND METHODS}

Embryos. The use of vertebrate animals for purposes of the project described here was reviewed and approved by the University of Minnesota Institutional Animal Care and Use Committee and conforms to NIH guidelines. Fertilized chicken eggs, pathogen-free White Leghorn 
crossed with Rhode Island Red, were obtained from the University of Minnesota Poultry Center. Eggs were incubated at $37^{\circ} \mathrm{C}$ for $3 \mathrm{~d}$, after which the embryos were removed from the shell and transferred to embryo culture chambers. The chambered embryos were maintained in a forced draft incubator at $37^{\circ} \mathrm{C}, 95 \%$ relative humidity, and $1 \% \mathrm{CO}_{2}$.

Drug treatment. Inhibitors of NO synthesis were administered to chick embryos as previously described (Wu et al., 1994). Briefly, $N^{\omega}$-nitro-Larginine (L-NoArg) or $N^{\omega}$-nitro-L-arginine methyl ester (L-NAME) obtained from Sigma (St. Louis, MO) was dissolved in saline at concentrations stated in Results. One hundred microliters of drug was spread over the vascularized chorioallantoic membrane of chambered chick embryos daily from embryonic day 9 (E9) to E16, which covers the period during which the retinotectal projection normally undergoes refinement. Control embryos received $N^{\omega}$-nitro-D-arginine methyl ester (D-NAME), the inactive enantiomer of L-NAME, or saline alone. It was shown previously that overall development of the embryos was not affected by these drug treatments (Wu et al., 1994). To test the effect of vasoconstriction, L-phenylephrine $\mathrm{HCl}$ (ICN Biomedicals, Aurora, $\mathrm{OH}$ ) was administered to embryos with the same protocol as used for inhibitors of NO synthesis.

Analysis of retinotectal topography. At E16, $0.2 \mu \mathrm{l}$ of $0.04 \mu \mathrm{m}$ yellowgreen fluorescent latex microspheres (Molecular Probes, Eugene, OR) was injected into a single small locus in the posterior region of the right tectum of embryos. For one experiment, younger embryos were injected with $0.05-0.2 \mu \mathrm{l}$ depending on their age. After $24 \mathrm{hr}$, embryos were perfused through the heart with $4 \%$ paraformaldehyde $/ 0.1 \mathrm{M}$ phosphate buffer, $\mathrm{pH}$ 7.3. The tracer-injected tectum and contralateral retina were dissected and immersed in fixative for $2 \mathrm{hr}$. Both tissues were mounted flat on microscope slides. Slides were examined by fluorescence microscopy. The outlines of the tissue and the positions of the tracer injections in the tecta or of the retrogradely labeled cells in the retinas were plotted by means of a computer interfaced to position encoders on the microscope stage.

The percentage of retrogradely labeled cells in the ganglion cell layer was determined in the center of the highest concentration of labeled cells. Retinas were counterstained for $1 \mathrm{~min}$ in $1.5 \times 10^{-6} \mu \mathrm{M}$ DAPI. Virtual 5- $\mu \mathrm{m}$-thick optical sections were constructed using Microtome (VayTek) within the Image-Pro Plus program (Media Cybernetics) from 10 deconvolved micrographs made at focal planes $0.5 \mu \mathrm{m}$ apart beginning at the inner surface of the ganglion cell layer. All DAPI-stained cells per field were counted, as were the number of cells with at least two microspheres. Four fields, each a square of $300 \mu \mathrm{m}$ per side, were counted and averaged per retina. The four nonoverlapping fields each had a corner positioned near the subjective center of the highest density of labeled cells. The position of each field was adjusted slightly when needed to avoid defects in the flat mount, making the cells uncountable. The percentage of microsphere-labeled cells was calculated from these counts. Results for the different treatment groups were compared using an unpaired $t$ test.

The scatter of retrogradely labeled cells across the retina was quantified. Retinas for this analysis were selected with similar tracer injections in the tectum in terms of position and size. A target-like overlay consisting of concentric rings at intervals of $1.3 \mathrm{~mm}$ was centered over the area with the greatest concentration of retrogradely labeled cells on retinal flat mounts. The number of labeled cells in each ring was counted. Results for the different treatment groups were compared by ANOVA.

Retrogradely labeled cells on the temporal sides of the retinas also were counted. The division between the nasal and temporal side was defined as a vertical line through the retina centered on the optic fissure. Results for the different treatment groups were compared using an unpaired $t$ test.

Nitric oxide synthase assay. NO synthase (NOS) activity in tecta from drug-treated embryos and in retina and tecta from normal, untreated embryos was determined biochemically as previously described (Bredt and Snyder, 1989; Ernst et al., 1999). Briefly, the conversion of $\left[{ }^{3} \mathrm{H}\right] \mathrm{L}-$ arginine to $\left[{ }^{3} \mathrm{H}\right] \mathrm{L}$-citrulline was used as a measure of NO generation. Fresh tissue was homogenized in buffer and centrifuged to separate a cytosolic fraction. Endogenous arginine was removed by passing the supernatant through a DOWEX AG50W-X8 column. NADPH and $\left[{ }^{3} \mathrm{H}\right] \mathrm{L}$-arginine with appropriate buffers were added to aliquots of the arginine-free cytosol containing $250 \mu \mathrm{g}$ of total protein. These reaction mixtures were incubated for $45 \mathrm{~min}$ at $37^{\circ} \mathrm{C}$. Reactions were stopped by the addition of EGTA, and unconverted arginine was removed by passage of the samples through another ion-exchange column. The $\left[{ }^{3} \mathrm{H}\right] \mathrm{L}-$ citrulline was measured in the flow-through by liquid scintillation spectroscopy. Data were compared by one-factor ANOVA.

\section{RESULTS}

\section{Normal refinement of retinotectal topography}

Previous studies used anterograde axonal tracing to show that the initial topography of the chick retinotectal projection is rough and is refined during subsequent development (McLoon, 1982; Nakamura and O'Leary, 1989). Although anterograde tracing is good for identification of axons with projections radically different from those found in the adult, it is not as useful for revealing the overall precision of the projection or subtle changes during the refinement process. Retrograde axonal tracing was used to better characterize the overall precision of the retinotectal projection and the timing of the refinement process. A single, focal injection of fluorescent microspheres was made into the posterior region of the right tectum in chicks ranging in age from E10 to E17. Twenty-four hours after a tracer injection, the left retinas were fixed and prepared as whole mounts. Using a fluorescence microscope, the distribution of retrogradely labeled ganglion cells was determined.

Refinement of the topography of the contralateral retinotectal projection takes place from E11 to E17 in chick. The broadest distribution of labeled cells was seen on E11 (referring to the age at which the retinas were fixed). At this age, there was a heavy concentration of retrogradely labeled cells spread over a large portion of the nasal side of the retina (Fig. 1 $A$ ). Also isolated, labeled cells were distributed across much of the retina including the temporal side. Beginning as early as E12, the central retina just above the optic fissure was devoid of retrogradely labeled cells. The area devoid of labeled cells became larger with increasing age (Fig. 1B,C). By E15, the majority of the retrogradely labeled cells were concentrated in a small area on the nasal side of the retina, a much smaller area than seen at earlier ages (Fig. $1 C)$. The adult projection pattern was achieved by E17, when retrogradely labeled cells were restricted to a small spot on the nasal side of the retina (Fig. 1D). Retrograde tracing (data not shown) and previous anterograde tracing studies (McLoon, 1982; Nakamura and O'Leary, 1989) indicate that the projection from the temporal side of the retina to anterior tectum undergoes a refinement similar to that of the projection from the nasal side of the retina during the same period of development. Because of problems with labeling fibers of passage, the results are cleaner for the projection from the nasal side of the retina, so the rest of this study focused on projections labeled by tracer injections to posterior tectum. Thus, refinement of the contralateral retinotectal projection includes elimination of radically aberrant projections, such as those from the temporal side of the retina to posterior regions of the tectum, as well as a more subtle improvement in the topographic precision of the projection. Refinement of the contralateral retinotectal projection takes place during the same period of development in which the transient ipsilateral retinotectal projection is normally eliminated (Williams and McLoon, 1991). This is also the same developmental period during which high levels of NO synthase are expressed in the tectum (Williams et al., 1994) and in which inhibition of NO synthesis prevented elimination of the ipsilateral retinotectal projection (Wu et al., 1994).

\section{Inhibition of nitric oxide synthesis}

Systemic administration of arginine analogs was tested for effectiveness in reducing NO synthesis in chick embryo tectum as a prelude to testing the role of nitric oxide in topographic refinement. Nitric oxide synthesis was assayed in a cytosol fraction of tectal tissue harvested from embryos treated with various doses of 

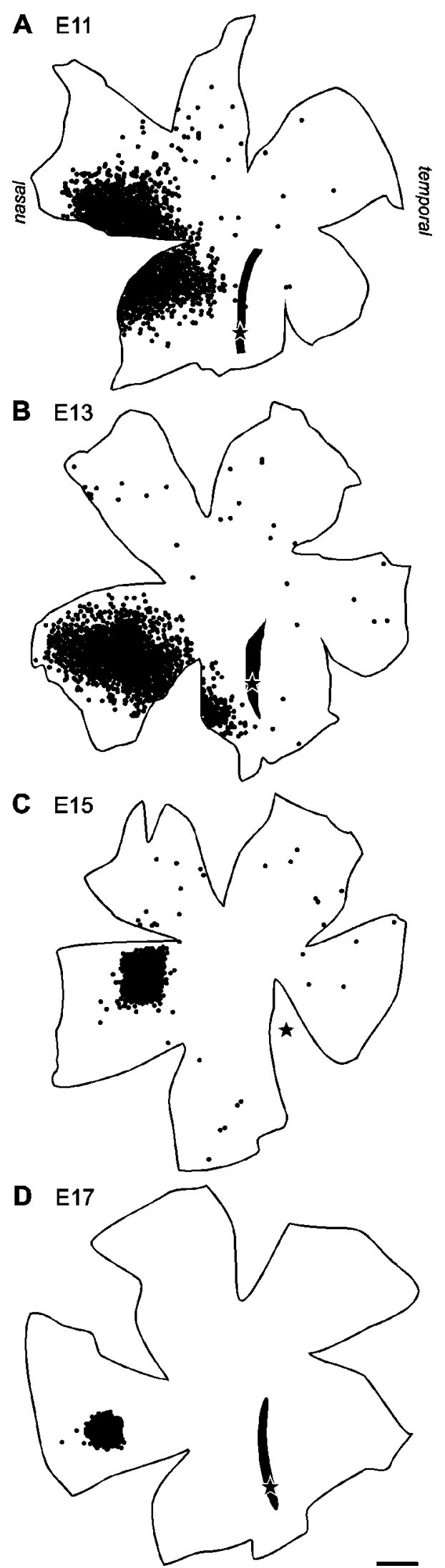

Figure 1. Improvement in the topographic precision of the retinotectal projection during normal development. The position of retrogradely labeled ganglion cells is indicated by dots on these enlarged tracings of retinal whole mounts from untreated embryos of different ages. The embryonic age at which each retina was fixed is indicated. Twenty-four

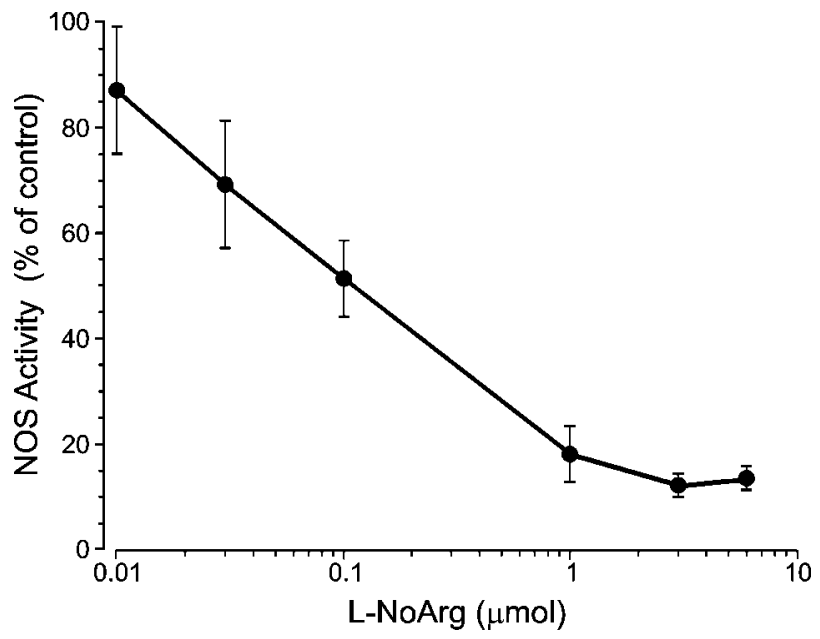

Figure 2. Dose-dependent reduction in NO synthase activity in tectum after treatment with L-NoArg. NO synthase activity was assayed in homogenates of tectum by measuring the conversion of $\left[{ }^{3} \mathrm{H}\right]$-arginine to $\left[{ }^{3} \mathrm{H}\right]$-citrulline. Twelve hours before harvesting the tecta for analysis, embryos were treated systemically with saline or L-NoArg at the doses indicated. Error bars indicate SE; $n=6$ for each data point.

the NO synthesis inhibitors L-NoArg or L-NAME and from control embryos either untreated or treated with D-NAME or saline. NO synthesis was assayed by measuring the conversion of $\left[{ }^{3} \mathrm{H}\right] \mathrm{L}$-arginine to $\left[{ }^{3} \mathrm{H}\right] \mathrm{L}$-citrulline. NO synthesis in tectal tissue from D-NAME or saline-treated embryos was not significantly different from untreated embryos at any dose tested ( $p=0.49$, $0.56)$. NO synthesis in tectal tissue from L-NoArg- or L-NAMEtreated embryos was significantly less than that of control embryos $(p<0.01$ for all doses tested). This reduction in NO synthesis was dose-dependent (Fig. 2). The most effective treatment was with $2 \mu \mathrm{mol}$ of L-NoArg, which reduced NO synthesis to $12.3 \pm 2.2 \%$ of the control value (Fig. 2). At the same dose, L-NoArg was more effective than L-NAME in inhibiting NO synthesis, and the maximum effectiveness of L-NoArg was greater than that for L-NAME (data not shown). Our previous study showed that L-NoArg and L-NAME reduced the level of NO synthesis in chick tectum consistent with the present results $(\mathrm{Wu}$ et al., 1994); the maximally effective dose, however, was not previously determined.

\section{Incomplete refinement of retinotectal topography with inhibition of nitric oxide synthesis}

The role of NO in refinement of retinotectal topography was assessed by daily administration of L-NoArg or L-NAME to chick embryos from E9 through E16, which covers the period of development during which refinement normally takes place. Control embryos were treated with saline or D-NAME during the same period. On E16, an age near the end of the refinement process, fluorescent latex microspheres were microinjected into a small region of a posterior tectum in each embryo. The embryos were fixed $24 \mathrm{hr}$ later. The retinas contralateral to the injected tecta

hours before preparation of these whole mounts, fluorescent latex microspheres were microinjected into a small spot in the posterior region of the tecta contralateral to these retinas. The precision of the topography progressively improves through a process of refinement from E12 to E17. The nasal side of each retina is on the left, and the temporal side is on the right. The $\star$ indicates the position of the optic fissure. Scale bar, $2 \mathrm{~mm}$. 


\section{A D-NAME (control)}

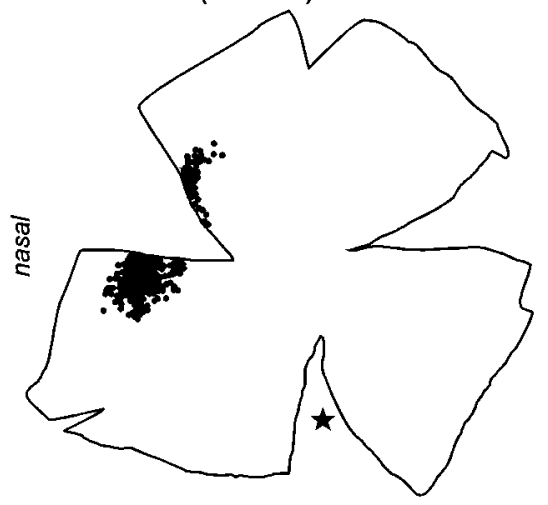

B L-NoArg

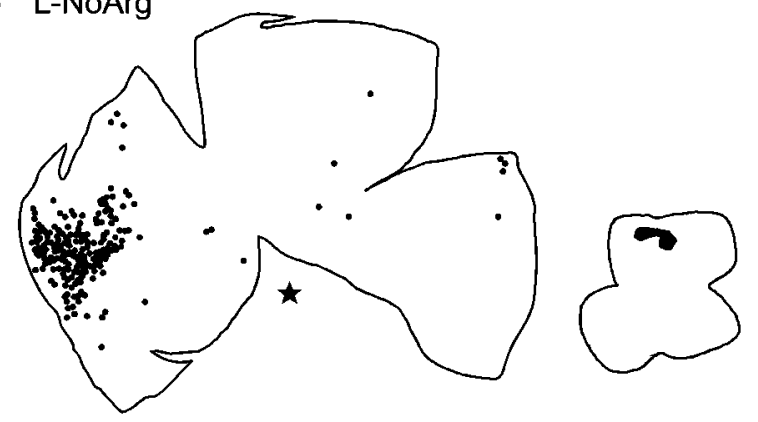

\section{L-NAME}
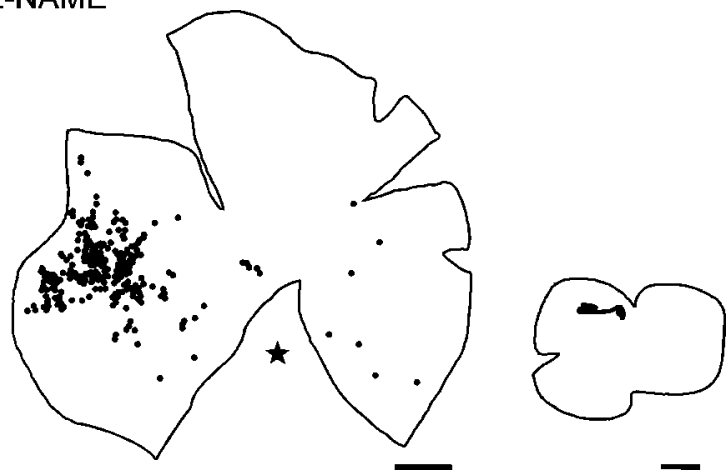

Figure 3. Incomplete refinement of retinotectal topography with inhibition of NO synthesis. The position of retrogradely labeled ganglion cells is indicated by dots on these enlarged tracings of retinal whole mounts. Embryos were treated daily from E9 through E16 with $10 \mu \mathrm{mol}$ of D-NAME ( $A$, control), $2 \mu \mathrm{mol}$ of L-NoArg $(B)$, or $10 \mu \mathrm{mol}$ of L-NAME (C). On E16, $24 \mathrm{hr}$ before preparation of these whole mounts, fluorescent latex microspheres were microinjected into a small spot in the posterior region of the tecta contralateral to these retinas. The small insets to the right of each retina are traces of whole mounts of the tecta with the injection sites indicated. Unlike controls, retrogradely labeled ganglion cells were distributed across much of the retina in drug-treated embryos. This indicates that the precision of the topography of the retinotectal projection did not undergo refinement in the absence of NO synthesis. The nasal side of each retina is on the left, and the temporal side is on the right. The $\star$ indicates the position of the optic fissure. Scale bars, $2 \mathrm{~mm}$.

were whole mounted and examined for the presence of microsphere-labeled ganglion cells, indicating that their axons projected to the region of the injection site in the tectum. High concentrations of microsphere-labeled ganglion cells were found in a focused region on the nasal side of the retina contralateral to the injected tectum in both control and experimental embryos (Fig. 3). In control and experimental embryos, the position of this high concentration of labeled cells was topographically appropri-

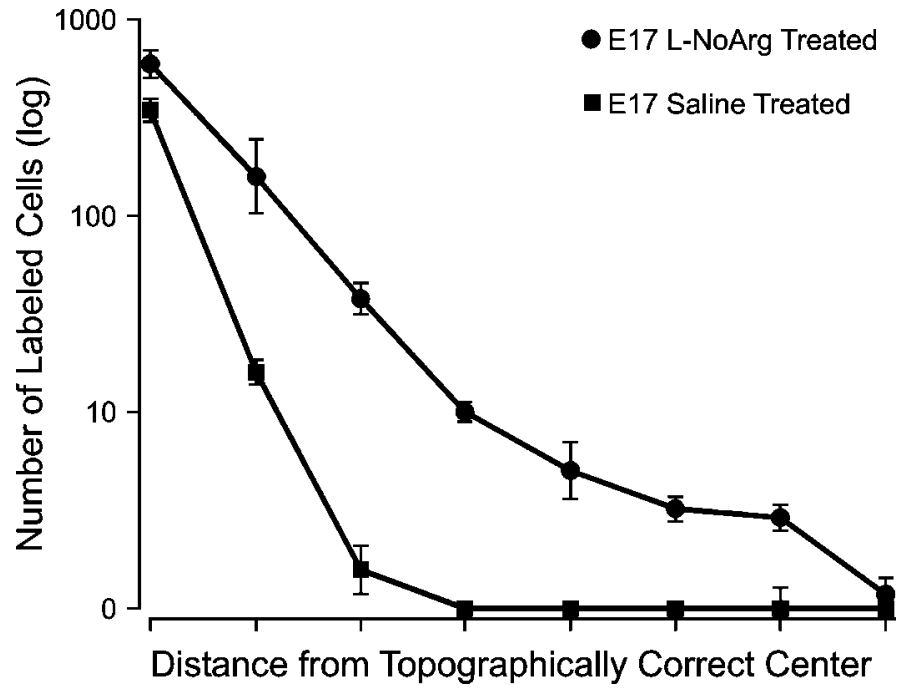

Figure 4. Scatter analysis of retrogradely labeled cells. The graph shows the number of retrogradely labeled ganglion cells with increasing distance from the area of the retina with the highest concentration of labeled cells. Labeled cells in retinas from embryos treated with (๑) $2 \mu$ mol of L-NoArg during the period of refinement were significantly more scattered than in retinas from ( $\square$ ) embryos treated with saline during the same period ( $p=$ 0.0001 ), indicating that inhibition of NO synthesis prevents complete refinement of topography. Unit of distance is a radial increment of 1.3 $\mathrm{mm}$ of retina.

ate for the site of the tectal injection. This indicates that the gross topography of the projection can be maintained through the refinement process, despite inhibition of NO synthesis.

Microsphere-labeled ganglion cells, however, were present across a larger area of the retina in embryos treated with L-NoArg or L-NAME than in control embryos (Fig. 3). Some labeled cells were as far afield as the temporal side of the retina in drug-treated embryos, which was rarely encountered in control embryos. Scatter analysis shows that inhibition of NO synthesis resulted in an overall loss of topographic precision and not just a persistence of radically aberrant projections (Fig. 4). The scatter of labeled cells in retinas from embryos treated with $2 \mu \mathrm{mol}$ of L-NoArg was significantly different from that for retinas from embryos treated with saline ( $p<0.0001 ; n=6$ per condition). The finite number of cells on the temporal side of the retina allowed easy quantitation of the effect of different drug doses. The number of labeled cells on the temporal side of the retina was directly dependent on the dose of L-NAME (Fig. 5) and was significantly greater than that for untreated, D-NAME or saline-treated embryos. The topography of the retinotectal projection after inhibition of NO synthesis resembled that seen before refinement (compare Fig. $1 A$ with $3 B, C)$. These results indicate that NO synthesis is involved in refinement of the topography of the contralateral retinotectal projection in chick.

Although inhibition of NO synthesis resulted in an increase in the number of labeled cells in topographically incorrect parts of the retina, it actually resulted in a reduction in the percentage of cells retrogradely labeled in the topographically correct part of the retina. After a spot injection of microspheres in the tectum of saline-treated embryos, the area of the retina with the highest concentration of retrogradely labeled cells constitutes the topographically correct projection to the injected site in the tectum. In retinas from saline-treated embryos, $78 \pm 4 \%$ of the cells in this region were labeled (Fig. 6). Labeling appeared to be very effi- 


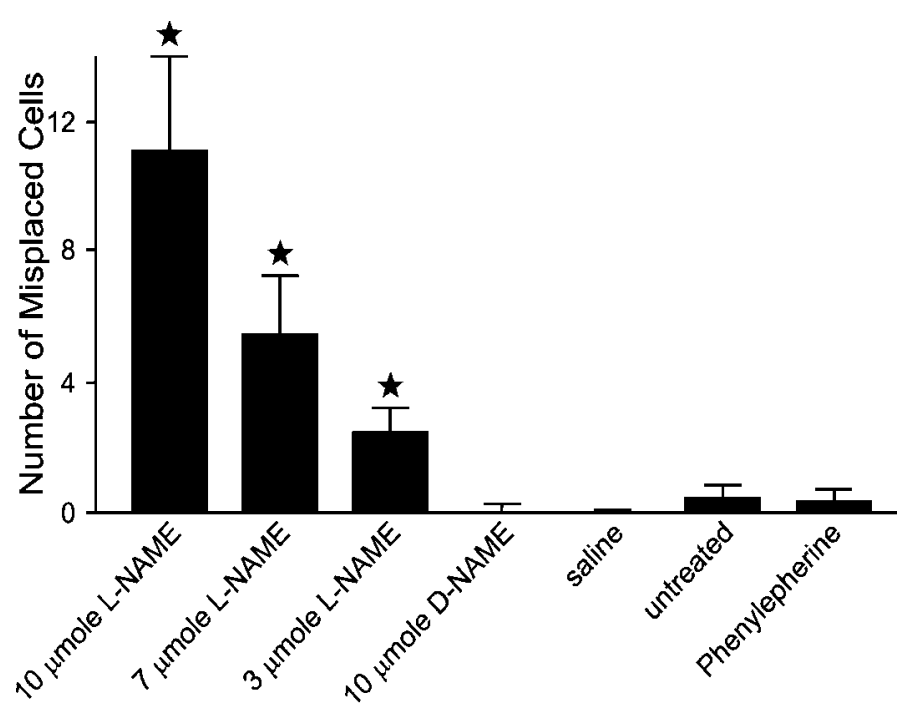

Figure 5. Dose-dependent change in retinotectal topography with inhibition of NO synthesis. The graph shows the number of retrogradely labeled ganglion cells on the temporal side of E17 retinas after microspheres were microinjected into a small spot in the posterior region of the tecta contralateral to the retinas analyzed. Experimental embryos were treated daily from E9 to E16 with doses of L-NAME as shown. Control embryos were treated with D-NAME, saline or were untreated. Another group of embryos was treated with $10 \mathrm{nmol}$ of phenylephrine $\mathrm{HCl}$ to test the effect of vasoconstriction on refinement. The division between nasal and temporal retina was deemed to be the optic fissure and a line that extended from the optic fissure into the dorsal retina. This cut to divide the two sides of the retina was made before the retinas were removed from the sclera. The $\star$ indicates results significantly different from each of the controls $(p<0.001)$. Error bars indicate SE; $n=5$ for each treatment group.

cient, because the best estimates indicate that $\sim 80 \%$ of the cells in the ganglion cell layer in the periphery of the chick retina at this age are ganglion cells (Chen and Naito, 1999). In embryos treated with $2 \mu \mathrm{mol}$ of L-NoArg during the period of refinement, however, only $59 \pm 7 \%$ of the cells were labeled in this region of the retina (Fig. 6). This $19 \%$ difference was significant ( $p=$ $0.002 ; n=6$ per condition). There was no significant difference between experimental and control retinas in the density of all cells in the ganglion cell layer in comparable regions of the retina $(p=0.44)$. This suggests that the difference in the number of labeled ganglion cells is not caused by a difference in ganglion cell death, which is consistent with our previous finding that blocking NO synthesis during this period of development does not alter ganglion cell death (Ernst et al., 1999). Therefore, the presence of fewer retrogradely labeled cells most likely means that some ganglion cells do not project to the topographically correct target after a reduction of NO synthesis during the period of refinement.

\section{Refinement of retinotectal topography after treatment with a vasoconstrictor}

NO induces vasodilatation in adult animals, and inhibitors of NO synthesis can result in vasoconstriction and increased blood pressure (Moncada et al., 1991; Kelly et al., 1995). Although we previously showed that blood vessels in the chorioallantoic membrane of embryos appeared unresponsive to the doses of NO synthesis inhibitors used for this study (Wu et al., 1994), the effects of blocking NO synthesis on the retinotectal projection could be attributable to subtle changes in blood flow. To test this, embryos were treated with phenylephrine, which results in vaso- constriction (Sheridan et al., 1999; Zhu et al., 1999). Embryos were treated daily from E9 to E16 with 100, 10, or $1 \mathrm{nmol}$ of phenylephrine. The two highest doses resulted in significant constriction of the vessels of the chorioallantoic membrane in E14 and older embryos, which was visible with a dissecting microscope. Eighty-three percent of the embryos treated with the 100 nmol dose died during the treatment period, and those embryos that lived appeared smaller than normal and unhealthy. Subsequent analysis focused on embryos that received the $10 \mathrm{nmol}$ dose, which showed normal development and mortality levels. On E16, fluorescent latex microspheres were microinjected into a small region of a posterior tectum in each embryo, and subsequently, the distribution of microsphere-labeled ganglion cells was analyzed in the contralateral retinas. The overall pattern appeared normal, and no significant increase in the number of labeled ganglion cells on the temporal side of the retina was observed (Fig. 5). Although further work is needed to better compare the duration of the phenylephrine effect with that of the NO synthesis inhibitors, these observations suggest that the effect of blocking NO synthesis on refinement of the topography of the retinotectal projection was not caused by changes in blood flow.

\section{Site of NO action in refinement of the retinotectal projection}

Using a systemic drug treatment to inhibit NO synthesis in embryos is preferable to some form of targeted drug delivery because it is much less invasive. Invasive procedures in embryos have many nonspecific effects, not the least of which is a high mortality rate. The difficulty in interpreting the results of systemic drug treatment, as with a genetic knock-out, is that the site of action is uncertain. In the case of refinement of the retinotectal projection, the most probable sites of NO action are the retina and the tectum. Previous studies, based on NADPH-diaphorase histochemistry, showed that NO synthase is expressed at high levels in the chick tectum during the developmental period in which the retinotectal projection is refined (Williams et al., 1994). Although it is established that NO synthase is expressed in cells of the mature chick retina (Fischer and Stell, 1999), information on the time of appearance of NO synthase in embryonic chick retina is incomplete and contradictory (Ientile et al., 1996; Paes de Carvalho et al., 1996; Goureau et al., 1997). To evaluate the possibility that retina is the site of NO action in this study, the activity of NO synthase was assayed in retina and tectum from normal embryos at various stages of development (from E6 to hatching). NO synthase activity was assayed by measuring the conversion of $\left[{ }^{3} \mathrm{H}\right]$-arginine to $\left[{ }^{3} \mathrm{H}\right]$-citrulline in cytosol fractions of tissue homogenates. At E6, NO synthase activity in tectum was low, and it progressively increased until near the end of development when it started to decrease (Fig. 7). In retina, NO synthase activity was also low at E6 (Fig. 7). Diaphorase histochemistry on fixed, sectioned retina showed that this activity was associated with ganglion cells, which would have just completed migration to the ganglion cell layer at this age (data not shown). Unlike in tectum, however, NO synthase activity in the retina during the period of refinement of the retinotectal projection (E12-E17) was almost undetectable, and it did not start to increase until near the end of development (Fig. 7). These findings suggest that the effect observed on refinement of the retinotectal projection as the result of systemic administration of NO synthesis inhibitors was attributable to a loss of NO synthesis in the tectum rather than in the retina. 

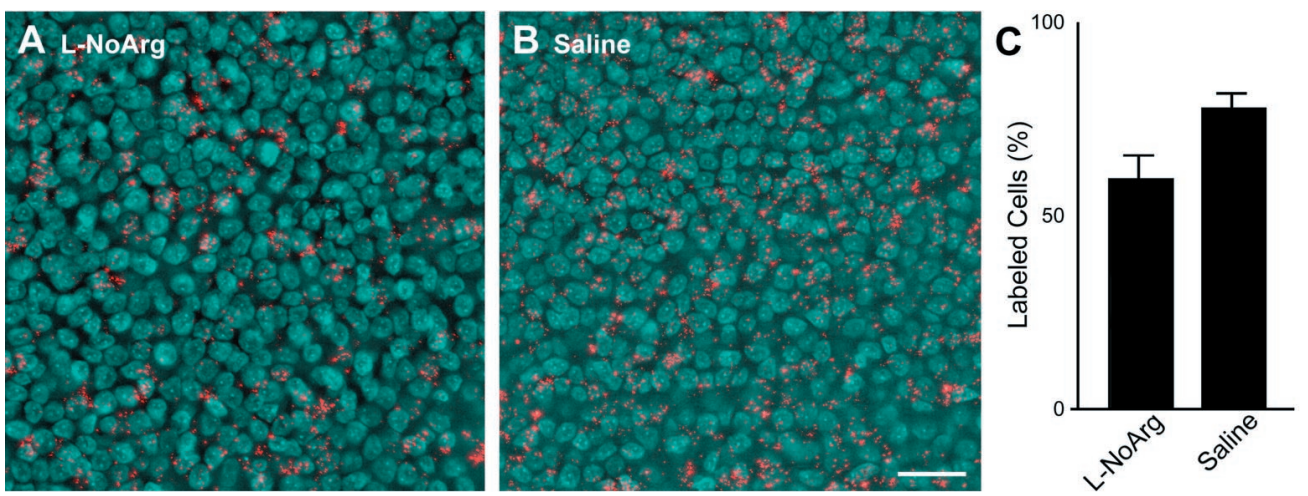

Figure 6. Reduction in the percentage of cells with topographically correct projections with inhibition of NO synthesis. Fluorescent micrographs show all cells in the ganglion cell layer stained with DAPI (blue) and cells retrogradely labeled (red) from an injection of microspheres in the contralateral tectum. The micrographs show the area of the retinas with the highest density of retrogradely labeled cells. Retinas were from embryos treated with 2 $\mu \mathrm{mol}$ of L-NoArg $(A)$ or saline $(B)$ during the period of refinement. Scale bar, $25 \mu \mathrm{m}$. $C$, A lower percentage of cells were retrogradely labeled after inhibition of NO synthesis $(p=0.002)$. Error bars indicate SE.

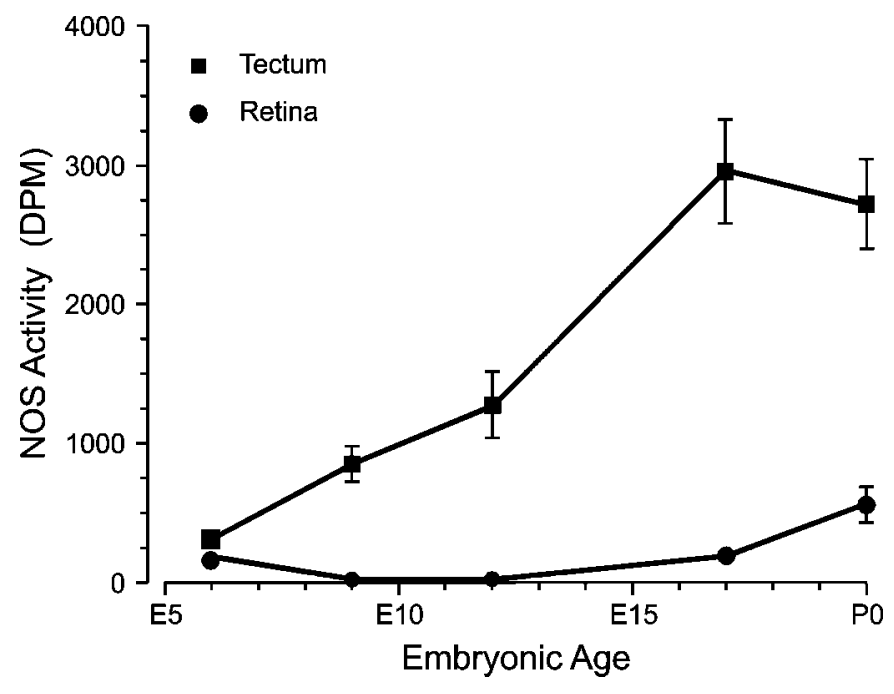

Figure 7. NO synthase activity in the retina and tectum during development. NO synthase activity was assayed in homogenates of retina and tectum from embryos ranging in age from E6 to P0 by measuring the conversion of $\left[{ }^{3} \mathrm{H}\right]$-arginine to $\left[{ }^{3} \mathrm{H}\right]$-citrulline. Aliquots of the cytosolic fraction of tissue samples containing $250 \mu \mathrm{g}$ of total protein were assayed. NO synthase levels are at background levels in the retina through much of the refinement period, whereas levels in the tectum peak during this period. Results are presented as the mean liquid scintillation spectroscopy reading in disintegrations per $\min (D P M)$ from three samples. Five retinas were pooled for each retinal sample. One tectum was used for each tectal sample. Results for tectum at each age were statistically different from one another $(p<0.001)$. Error bars indicate SE. There was no significant difference in the results for E6, E9, and E10 retina $(p>0.05)$; results for E17 and P0 retina were significantly different from each of the younger ages $(p<0.01$ and $p<0.001$, respectively). There was no significant difference in the result for E6 retina and E6 tectum $(p>0.05)$; for all other ages, results for retina and tectum were significantly different $(p<0.0001)$.

\section{DISCUSSION}

The adult pattern of retinal axon connections in the brain arises during development through refinement of a less organized projection. In the developing chick, this process was examined previously using anterograde tracing of retinal axons, which showed that radically aberrant projections are eliminated during visual system development (McLoon, 1982; Nakamura and O'Leary, 1989). The present study used retrograde tracing to more clearly demonstrate the progressive refinement of the contralateral retinotectal projection. This refinement took place from E12 to E17 and included elimination of radically inappropriate projections, such as those from the temporal side of the retina to posterior regions of the tectum, as well as a more subtle improvement in the topographic precision of the projection. A similar refinement takes place in developing rodents, where the initial topography of the projection is less organized than in chick (Simon and O'Leary, 1992), and during regeneration of the goldfish retinotectal projection, where the initial projection is more precise than in chick (Matsumoto et al., 1987; Meyer and Kageyama, 1999).

The central retina showed the first evidence of refinement in chick, suggesting that maturation of the retina and not the tectum drives refinement of topography. Aberrantly projecting ganglion cells disappeared from central retina first and then from progressively more peripheral retina. Retinal development proceeds in a central to peripheral pattern (Kahn, 1974; Prada et al., 1991), whereas the tectum develops in an anterior to posterior pattern (LaVail and Cowan, 1971; Rager, 1980). The temporal side of the retina projects to anterior regions of the tectum. If tectal maturation drove refinement, then aberrant projections would be expected to disappear first from temporal rather than central retina. Although the developmental state of the retina appears to be key for initiating topographic refinement, the molecular mechanisms driving refinement are still poorly defined.

Nitric oxide synthase is active in the developing tectum at the same time refinement of the retinotectal projection takes place. Previously, it was shown that NOS is expressed in the chick tectum during the period of refinement using diaphorase histochemistry and Northern blotting methods (Williams et al., 1994). In the present study, NOS activity in chick tectum was detected using a biochemical assay. NOS activity peaked during the same period in which the retinotectal projection undergoes refinement. Similar results were reported for developing rodent tectum as well (Tenorio et al., 1995; Campello-Costa et al., 2000). Diaphorase histochemistry showed that NOS is expressed in the retinorecipient layers of the developing chick tectum and that its expression is dependent on retinal innervation, suggesting that retinal axons synapse on cells that express NOS (Williams et al., 1994). Thus, NOS has a spatial and temporal expression pattern consistent with NO having a role in refinement of the retinotectal projection.

Here we showed that reducing NO synthesis prevented refine- 
ment of the topography of the contralateral retinotectal projection. Systemic administration of the arginine analogs L-NoArg or L-NAME reduced NOS activity in the tectum in a dosedependent manner. Administration of these drugs during the period of refinement prevented the loss of topographically aberrant retinotectal projections and the improvement in the precision of the topography of the projection that normally takes place during this period. This effect was dose-dependent. These results show that NO is normally involved in refinement of the topography of the chick retinotectal projection.

Treatment with inhibitors of NO synthesis during the period of refinement resulted in a lower percentage of ganglion cells retrogradely labeled in the topographically correct region of the retina. This difference was not caused by increased cell death. Retinal ganglion cells require central connections to survive through the period of refinement (Hughes and McLoon, 1979). Thus, the ganglion cells that do not have topographically correct projections after inhibition of NO synthesis are presumably maintained via inappropriate connections. Other studies have shown that retinal axons identify their topographically correct targets in the tectum in part through the interaction of positional labels expressed by the retinal ganglion cells with complementary labels expressed by the tectal cells (for review, see O'Leary and Wilkinson, 1999). The present findings indicate that in the absence of NO synthesis, retinal axons can maintain inappropriate tectal connections in spite of a mismatch in positional labels.

$\mathrm{NO}$ is involved in refinement of some but not all retinofugal projections. Segregation of the retinotectal projection from the two eyes has been linked to NO synthesis in chick and rodents (Wu et al., 1994, 2000; Vercelli et al., 2000; Campello-Costa et al., 2000). Blocking NO in developing ferret, however, did not affect segregation of the projection from the two eyes to the lateral geniculate nucleus, but it did prevent segregation of on/off pathways in the retinogeniculate projection (Cramer et al., 1996; Cramer and Sur, 1999). Additionally, inhibition of NO synthesis did not prevent development of eye-specific stripes when two eyes were experimentally induced to innervate a single tectum in frog (Renteria and Constantine-Paton, 1999). At this point, there are no obvious features common to retinofugal systems that use or that do not use NO in refinement. A quantitative analysis of the ipsilateral retinotectal projection in chick showed that at most $30 \%$ of this projection could be rescued by inhibiting NO synthesis during refinement (Ernst et al., 1998). This indicates that mechanisms not involving $\mathrm{NO}$ also regulate refinement of this system. In cases where blocking NO did not appear to affect refinement, it may be that $\mathrm{NO}$ is normally active, but in the absence of $\mathrm{NO}$, the other mechanisms can compensate completely.

A well established action of NO in mature vertebrates is vasodilation (for review, see Moncada et al., 1991). We previously showed that the NO synthesis inhibitors used in this study had no obvious effects on the vasculature of the chorioallantoic membrane during the period of this study (Wu et al., 1994). To further eliminate the possibility that vasoconstriction after the loss of NO synthesis was responsible for the change in refinement, embryos were treated with the vasoconstrictor phenylephrine during the period of refinement. The topography of the retinotectal projection in these embryos underwent normal refinement. This result suggests that the effect of blocking NO synthesis on refinement was not due to effects on the vasculature. This is in agreement with a previous study that concluded that changes in blood pressure were not responsible for the changes observed in retinal axon lamination in the developing ferret geniculate after a reduction in NO synthesis (Cramer and Sur, 1996). Another study that examined the activity of individual cortical neurons concluded that altering NO synthesis had neuronal effects independent of vascular effects (Kara and Friedlander, 1999). Ruling out blood flow effects suggests that the main site of NO action relative to refinement is neuronal.

Because the NO synthesis inhibitors were administered systemically, the site of NO action relative to refinement is undetermined. NO is known to affect synaptic function in mature retina (for review, see Cudeiro and Rivadulla, 1999). Thus, it is possible that the alterations in the retinotectal projection observed after inhibition of NO synthesis were attributable to a retinal effect. However, NOS activity was assayed in retina during development and found to be extremely low during the period of refinement of the retinotectal projection. It is noteworthy that retina did exhibit elevated NOS activity very early in development when the ganglion cells are beginning differentiation. Diaphorase histochemistry showed that this early peak in NOS activity is associated with the developing ganglion cells. The role of NO in the early retina is unknown. A significant level of NOS activity does not develop in the retina until the retinal circuitry is well developed, which is near the end of the period of refinement. It is during this period that NOS activity is highest in the tectum, making it likely that the site of NO action relative to refinement is in the tectum.

In summary, this study showed that NO has a role in development of the topography of the retinotectal projection. The mechanism of NO action relative to refinement of the retinotectal projection remains unclear. NO appears to be synthesized by tectal cells in response to activation of NMDA receptors by retinal axons (Williams et al., 1994; Ernst et al., 1999). The dominant input to a given tectal neuron is presumably by retinal axons with appropriate connections, and it is this projection that can depolarize a cell sufficiently to activate the NMDA receptors. It is likely that NO acts as a retrograde messenger from tectal cells back to the retinal terminals and that it initiates retraction of inappropriately connected retinal axons. It has been shown in tissue culture that NO can initiate retraction of developing retinal axons (Renteria and Constantine-Paton, 1996; Ernst et al., 2000). Because NO is a gas that diffuses freely (Wood and Garthwaite, 1994; Lancaster, 1997), it seems unlikely that it is targeted specifically to inappropriately connected terminals. Terminals with correct projections must be protected from NO-induced retraction. It could be that recent activity somehow confers protection from NO, possibly through selective action of neurotrophin released from the tectal cell (Boulanger and Poo, 1999; Ernst et al., 2000). Alternatively, the action of NO relative to refinement could be within the cell in which it is synthesized. NO has a role in hippocampal long-term potentiation (LTP) (Arancio et al., 1996; Son et al., 1996), a form of plasticity with many similarities to developmental refinement of connections. In LTP, NO can act postsynaptic within the cell in which it is synthesized to alter response to a synaptic input rather than acting as a retrograde messenger (Ko and Kelly, 1999). Further work is needed to clarify the cellular mechanisms of NO action relative to refinement of developing neuronal connections.

\section{REFERENCES}

Arancio O, Kiebler M, Lee C, Lev-Ram V, Tsien R, Kandel E, Hawkins R (1996) Nitric oxide acts directly in the presynaptic neuron to produce long-term potentiation in cultured hippocampal neurons. Cell 87:1025-1035. 
Boulanger L, Poo MM (1999) Presynaptic depolarization facilitates neurotrophin-induced synaptic potentiation. Nat Neurosci 2:346-351.

Bredt DS, Snyder SH (1989) Nitric oxide mediates glutamate-linked enhancement of cGMP levels in the cerebellum. Proc Natl Acad Sci USA 86:9030-9033.

Campello-Costa P, Fosse AM, Ribeiro JC, Paes-de-Carvalho R, Serfaty CA (2000) Acute blockade of nitric oxide synthesis induces disorganization and amplifies lesion-induced plasticity in the rat retinotectal projection. J Neurobiol 44:371-381.

Chen Y, Naito J (1999) A quantitative analysis of cells in the ganglion cell layer of the chick retina. Brain Behav Evol 53:75-86.

Cowan WM, Fawcett JW, O'Leary DMM, Stanfield BB (1984) Regressive events during neurogenesis. Science 225:1258-1265.

Cramer KS, Sur M (1999) The neuronal form of nitric oxide synthase is required for pattern formation by retinal afferents in the ferret lateral geniculate nucleus. Dev Brain Res 116:79-86.

Cramer KS, Angelucci A, Hahm JO, Bogdanov MB, Sur M (1996) A role for nitric oxide in the development of the ferret retinogeniculate projection. J Neurosci 16:7995-8004.

Cudeiro J, Rivadulla C (1999) Sight and insight-on the physiological role of nitric oxide in the visual system. Trends Neurosci 22:109-116.

Ernst AF, Jurney WM, McLoon SC (1998) Mechanisms involved in development of retinotectal connections: roles of Eph receptor tyrosine kinases, NMDA receptors and nitric oxide. Prog Brain Res 118:115-131.

Ernst AF, Wu HH, El-Fakahany EE, McLoon SC (1999) NMDA receptor-mediated refinement of a transient retinotectal projection during development requires nitric oxide. J Neurosci 19:229-235.

Ernst AF, Gallo G, Letourneau PC, McLoon SC (2000) Stabilization of growing retinal axons by the combined signaling of nitric oxide and brain-derived neurotrophic factor. J Neurosci 20:1458-1469.

Fischer AJ, Stell WK (1999) Nitric oxide synthase-containing cells in the retina, pigmented epithelium, choriod and sclera of the chick eye. J Comp Neurol 405:1-14.

Goureau O, Regnier-Ricard F, Jonet L, Jeanny J-C, Courtois Y, ChanyFournier F (1997) Developmental expression of nitric oxide synthase isoform I and III in chick retina. J Neurosci Res 50:104-113.

Hughes WF, McLoon SC (1979) Ganglion cell death during normal retinal development in the chick: comparisons with cell death induced by early target field destruction. Exp Neurol 66:587-601.

Ientile R, Malecka B, Picciurro V, Naso A, Pedale S, Macaione S (1996) Nitric oxide synthase in chick embryo retina during development. FEBS Lett 379:82-84.

Kahn AJ (1974) An autoradiographic analysis of the time of appearance of neurons in the developing chick retina. Dev Biol 38:30-40.

Kara P, Friedlander MN (1999) Arginine analogs modify signal detection by neurons in the visual cortex. J Neurosci 19:5528-5548.

Kelly PA, Ritchie IM, Arbuthnott GW (1995) Inhibition of neuronal nitric oxide synthase by 7-nitroindazole: effects upon local cerebral blood flow and glucose use in the rat. J Cereb Blood Flow Metab $15: 766-773$.

Ko GY, Kelly PT (1999) Nitric oxide acts as a postsynaptic signaling molecule in calcium/calmodulin-induced synaptic potentiation in hippocampal CA1 pyramidal neurons. J Neurosci 19:6784-6794.

Lancaster Jr JR (1997) A tutorial on the diffusibility and reactivity of free nitric oxide. Nitric Oxide 1:18-30

Land PW, Lund RD (1979) Development of the rat's uncrossed retinotectal pathway and its relation to plasticity studies. Science 205:698-700.

LaVail JH, Cowan WM (1971) The development of the chick optic tectum. II. Autoradiographic studies. Brain Res 28:421-441.

Matsumoto N, Kometani M, Nagano K (1987) Regenerating retinal fibers of the goldfish make temporary and unspecific but functional synapses before forming the final retinotopic projection. Neuroscience 22:1103-1110.

McLoon SC (1982) Alterations in precision of the crossed retinotectal projection during chick development. Science 215:1418-1420.
McLoon SC, Lund RD (1982) Transient retinofugal pathways in the developing chick. Exp Brain Res 45:277-284.

Meyer RL, Kageyama GH (1999) Large-scale synaptic errors during map formation by regenerating optic axons in the goldfish. J Comp Neurol 409:299-312.

Moncada S, Palmer RM, Higgs EA (1991) Nitric oxide: physiology, pathophysiology and pharmacology. Pharmacol Rev 43:109-142.

Nakamura H, O'Leary DDM (1989) Inaccuracies in initial growth and arborization of chick retinotectal axons followed by course corrections and axon remodeling to develop topographic order. J Neurosci 9:3776-3795.

O'Leary DD, Wilkinson DG (1999) Eph receptors and ephrins in neural development. Curr Opin Neurobiol 9:65-73.

O'Leary DDM, Gerfen CR, Cowan WM (1983) The development and restriction of the ipsilateral retinofugal projection in the chick. Dev Brain Res 10:93-109.

Paes de Carvalho R, de Faria MH, do Nascimento JLM, Hokoc JN (1996) Development of NADPH-diaphorase in the avian retina: regulation by calcium ions and relation to nitric oxide synthase. J Neurochem 67:1063-1071.

Prada C, Puga J, Perez-Mendez L, Lopez R, Ramirez G (1991) Spatial and temporal patterns of neurogenesis in the chick retina. Eur $\mathrm{J}$ Neurosci 3:559-569.

Rager G (1980) Development of the retinotectal projection in the chicken. Berlin: Springer.

Renteria R, Constantine-Paton M (1996) Exogenous nitric oxide causes collapse of retinal ganglion cell axonal growth cones in vitro. J Neurobiol 29:415-428.

Renteria R, Constantine-Paton M (1999) Nitric oxide in the retinotectal system: a signal but not a retrograde messenger during map refinement and segregation. J Neurosci 19:7066-7076.

Sheridan BC, McIntyre RC, Meldrum DR, Fullerton DA (1999) L-arginine attenuates endothelial dysfunction in endotoxin-induced lung injury. Surgery 125:33-40.

Simon DK, O'Leary DDM (1992) Development of topographic order in the mammalian retinocollicular projection. J Neurosci 12:1212-1232.

Son H, Hawkins R, Martin K, Kiebler M, Huang P, Fishman M, Kandel $\mathrm{E}$ (1996) Long-term potentiation is reduced in mice that are doubly mutant in endothelial and neuronal nitric oxide synthase. Cell 87:1015-1023.

Tenorio F, Giraldi-Guimaraes A, Mendez-Otero R (1995) Developmental changes of nitric oxide synthase in the rat superior colliculus. J Neurosci Res 42:633-637.

Vercelli A, Garbossa D, Biasiol S, Repici M, Jhaveri S (2000) NOS inhibition during postnatal development leads to increased ipsilateral retinocollicular and retinogeniculate projections in rats. Eur J Neurosci 12:473-490.

Williams CV, McLoon SC (1991) Elimination of the transient ipsilateral retinotectal projection is not solely achieved by cell death in the developing chick. J Neurosci 11:445-453.

Williams CV, Nordquist D, McLoon SC (1994) Correlation of nitric oxide synthase expression with changing patterns of axonal projections in the developing visual system. J Neurosci 14:1746-1755.

Wood J, Garthwaite J (1994) Models of the diffusional spread of nitric oxide: Implications for neural nitric oxide signaling and its pharmacological properties. Neuropharmacology 33:1235-1244.

Wu HH, Williams CV, McLoon SC (1994) Involvement of nitric oxide in the elimination of a transient retinotectal projection in development. Science 265:1593-1596.

Wu HH, Cork RJ, Huang PL, Shuman DL, Mize RR (2000) Refinement of the ipsilateral retinocollicular projection is disrupted in double endothelial and neuronal nitric oxide synthase gene knockout mice. Dev Brain Res 120:105-111.

Zhu BH, Guan YY, He H, Lin MJ (1999) Erigeron breviscapus prevents defective endothelium-dependent relaxation in diabetic rat aorta. Life Sci 65:1553-1559. 